\title{
PROTEÇÃO INTERNACIONAL AOS REFUGIADOS AMBIENTAIS
}

\author{
Aklla Guimarães Sales ${ }^{1} *$ \\ Raul Miguel Freitas de Oliveira ${ }^{2} * *$
}

\section{RESUMO:}

O Direito Internacional prevê um rol de situações nas quais se caracteriza o deslocamento forçado, todavia, não estão configurados nessa classificação os chamados "refugiados ambientais". Neste artigo, busca-se analisar se existe uma efetiva proteção internacional a este grupo de refugiados. Chega-se a conclusão de que as normas internacionais são restritivas e lacunosas, sendo flagrante a violação sofrida pelos "refugiados ambientais", tendo em vista que não há instrumentos de garantia capazes de tutelar seus direitos e a sua própria dignidade humana.

Palavras-chave: Refugiados Ambientais. Direito internacional. Migrações. Dignidade Humana. Direitos Humanos.

\section{INTERNATIONAL PROTECTION FOR ENVIRONMENTAL REFUGEES}

\section{ABSTRACT:}

The International law provides a roll of situations in which forced displacement is displayed, however, are not configured in this classification the environmental refugees. In this article, investigate whether there is effective international protection in this refugee group. It is concluded that international standards are restrictive and lacunar, being blatant the violation suffered by "environmental refugees", since there are no instruments of guarantee allowed by their legal rights and their own human dignity.

Keywords: Environmental Refugees. International Right. Migrations. Human Dignity. Human Rights.

\section{INTRODUÇÃO}

Ao analisar a história do mundo é possível perceber que as migrações por diversas razões sempre existiram, todavia, é notório que nos últimos anos o índice de deslocamento forçado aumentou significativamente, dentre os principais motivos estão os desastres ambientais, sejam eles causados pelo homem ou pela própria natureza.

\footnotetext{
${ }^{1}$ Mestranda do Programa de Pós Graduação em Direito da Faculdade de Direito de Ribeirão Preto da Universidade de São (FDRP/USP) e pós-graduanda em Direito Público e Cidadania pelo Centro Universitário de São Paulo (UNISAL), akllaguimaraes@ usp.br.

${ }_{2}^{2}$ Professor Doutor de Direito Ambiental da Faculdade de Direito de Ribeirão Preto da Universidade de São Paulo (FDRP/USP), raul.miguel@usp.br.
} 
Estudos comprovam que grande é o número de pessoas que deixam o país de sua origem ou nacionalidade por já não terem condições de vida diante de catástrofes ambientais, e assim, migram para outros locais à procura de ajuda humanitária.

Em contrapartida, um grande problema apresenta-se neste contexto: a falta de previsão desta categoria nos documentos internacionais de proteção aos refugiados. Assim, as pessoas que são forçadas a se deslocarem de seus países por questões ambientais encontramse em situação de irregularidade nos países que as recebem e consequentemente em constante risco no que diz respeito à violação de seus direitos humanos e fundamentais, bem como da sua própria dignidade.

O meio ambiente é tema de grande destaque nas agendas internacionais atuais, visto que cada vez mais se procura formas de proporcionar o meio ambiente ecologicamente equilibrado, tendo como pressupostos o fato de que os recursos naturais são limitados e que a ação humana pode causar diretamente a degradação ambiental. Neste ínterim, é preciso haver uma especial preocupação com as pessoas que estão sendo atingidas pelos problemas ambientais, a ponto de terem que deixar suas casas involuntariamente e buscarem ajuda humanitária e condições de vida em outro país.

Por meio de uma análise bibliográfica e levantamento de dados, busca-se compreender como tem sido a proteção internacional aos refugiados ambientais, já que esta categoria não está prevista nos instrumentos normativos relativos a esta temática e por fim, destacar a necessidade e a importância da criação de um documento internacional capaz de assegurar a tutela dos direitos dos migrantes desta categoria.

\section{MIGRAÇÕES INTERNACIONAIS E DIREITO INTERNACIONAL DOS REFUGIADOS}

Inicialmente, deve-se observar que as migrações internacionais é tema de grande destaque atualmente e um dos principais motivos para isso é o grande fluxo migratório que passou a ocorrer em todo o mundo desde a segunda metade do século $\mathrm{XX}$ e mais intensivamente a partir do século XXI.

A migração pode ser entendida basicamente como o "cruzamento da fronteira de uma unidade política ou administrativa por certo período mínimo" (CASTLE, 2003, p. 16). É 
o deslocamento de um ou mais indivíduos interna ou externamente, sendo esta última a migração internacional, por incorrer no deslocamento de um país para outro.

O migrante se difere do visitante, que se desloca para um determinado lugar por curto período de tempo, geralmente pré-determinado e sem expectativa de ali constituir uma nova vida. O migrar implica estabelecer residência, e para tanto existem muitas exigências que dependerão muitas vezes do destino para onde se pretende ir, o tempo de residência no local e as motivações que ensejaram a migração.

Sejam internas ou externas, as migrações podem ocorrer de forma voluntária, cujas razões para o deslocamento são diversas, sendo a busca por melhor qualidade de vida uma das mais recorrentes; forçada, nas quais se enquadram os refugiados e os requerentes de asilo; e por meio do tráfico de pessoas, cujo deslocamento do indivíduo pode ocorrer tanto voluntariamente, mas por engano ou contra sua vontade.

Tendo em vista que o presente artigo se limita a análise de uma categoria de migração forçada, o refugiado ambiental, faz-se necessária a breve abordagem da evolução do conceito geral de refugiados e, consequentemente, seu reconhecimento e proteção no direito internacional.

A figura do refúgio não se confunde com o asilo. Ao contrário do segundo instituto que surgiu na Antiguidade Clássica, o primeiro passou a ser regulamentado somente no século XX, especialmente após a Primeira Guerra Mundial. Materialmente, além de outras distinções, ambos se diferenciam, pois, enquanto que o asilo, seja territorial ou diplomático, está ligado estritamente a uma perseguição política e sob uma perspectiva regional, o refugio tem aplicação universal e mais abrangente no tocante ao requisito "perseguição", que pode ser por: "raça, religião, opinião política, pertencimento a um determinado grupo social e nacionalidade". (PEREIRA, 2009, p.65).

A Organização Internacional para Migrações (OIM) traz o seguinte conceito para migrações forçadas:

Termo geral usado para caracterizar o movimento migratório em que existe um elemento de coação, nomeadamente ameaças à vida ou à sobrevivência, quer tenham origem em causas naturais, quer em causas provocadas pelo homem (por ex., movimentos de refugiados e pessoas internamente deslocadas, bem como pessoas deslocadas devido a desastres naturais ou ambientais, químicos ou nucleares, fome 
ou projetos de desenvolvimento) (ORGANIZAÇÃO INTERNACIOAL PARA AS MIGRAÇÕES, 2009, p. 41).

Holzhacker afirma que embora as primeiras legislações sobre a condição do refugiado tenham sido elaboradas no século XVII, foi somente no século XX que se passou a buscar uma definição para o termo e enquadramento para essa categoria. Segundo a autora, incialmente o refugiado era entendido como aquele que pertencia a um determinado grupo que estava "efetivamente privado da proteção formal do governo de seu país" (2018, p.42), sendo posteriormente estendido este conceito àqueles que eram vítimas de eventos sociais e políticos.

Em 1951, importante documento foi promulgado: a Convenção Relativa ao Estatuto dos Refugiados (CRER), considerada Carta Magna do Direito Internacional dos Refugiados e que em seu artigo $1^{\circ}$ define refugiado como toda pessoa que:

[...] temendo ser perseguida por motivos de raça, religião, nacionalidade, grupo social ou opiniões políticas, se encontra fora do país de sua nacionalidade e que não pode ou, em virtude desse temor, não quer valer-se da proteção desse país, ou que, se não tem nacionalidade e se encontra fora do país no qual tinha sua residência habitual em consequência de tais acontecimentos, não pode ou, devido ao referido temor, não quer voltar a ele.

Embora reconhecendo a figura do refugiado, este documento limitou sua abrangência somente aos casos ocorridos antes de $1^{\circ}$ de janeiro do ano de 1951 e somente na Europa ou na a Europa e outros locais, dispondo assim de duas limitações: temporal e geográfica. Mais tarde, em 1967, o Protocolo Relativo ao Estatuto dos Refugiados, aprovado em Nova Iorque EUA suprimiu a limitação temporal estendendo a definição para todos os casos posteriores tornando um mandado universal de proteção aos refugiados. (HOLZHACKER, 2018).

Não obstante, outros importantes documentos surgiram, como a Declaração de Cartagena de 1984, que adotou uma definição mais abrangente tendo como pressuposto para configuração a condição do país de origem e não do indivíduo e também a Convenção da Organização de Unidade Africana, de 1974 (OUA), sendo ambos os documentos regionais, os quais têm adotado definições complementares a fim de adequar o reconhecimento e proteção dos refugiados à realidade local.

A proteção internacional dos refugiados tem por fundamentos os seguintes princípios: princípio da proteção internacional da pessoa humana (previsto no artigo 14 
DUDH e no preâmbulo da CRER; intrínseco à pessoa humana e requisito mínimo para o exercício de seus direitos e garantias fundamentais); cooperação e solidariedade internacionais (comunhão de esforços entre os Estados complementando e efetivando o princípio anterior); não devolução ou non-refoulement (proibição de devolução de um solicitante de refúgio deixando-o desprotegido frente a perseguição sofrida); princípio da boafé (estrito e harmonioso cumprimento das normas acordadas internacionalmente); supremacia do direito de refúgio (o Estado que concede o refúgio exerce sua soberania e o cumpre as normas internacionais de proteção à pessoa humana); unidade familiar (dever de proteção das famílias); e, por fim, princípio da não discriminação (PEREIRA, 2009).

Atualmente ainda se utiliza internacionalmente o conceito de refugiados trazido pela Convenção de 1951, cujos requisitos básicos para enquadramento além da extraterritorialidade, são: as razões de fundado temor de perseguição por motivos diversos, conforme disposto no artigo supracitado ou em casos de grave e generalizada violação aos direitos humanos.

Veja-se que existem apenas duas hipóteses de enquadramento, sendo que no primeiro caso, basta que haja ameaça ao direito, não sendo necessário que já esteja ocorrendo a perseguição. Na segunda hipótese, a grave e generalizada violação aos direitos humanos diz respeito aos casos cuja situação foi provocada pela própria ação humana.

Destacam-se três elementos essenciais para a configuração e possibilidade de concessão de refúgio: a perseguição, o fundado temor e a extraterritorialidade. A perseguição pode ser em razão de opiniões políticas, raça, religião, nacionalidade ou grupo social. De acordo com o ACNUR - Alto Comissariado nas Nações Unidas para os Refugiados, a perseguição neste caso pode ser compreendida como toda e qualquer possibilidade de ameaça à vida ou às liberdades civis dos indivíduos. Todavia, sua definição ainda é tema de grandes debates. O perseguidor, embora majoritariamente seja o Estado, na pratica não se limita somente a este, o que corrobora a lacuna presente na definição das hipóteses de incidência deste instituto jurídico (PEREIRA, 2009).

O fundado temor pode estar relacionado tanto ao receio ou insegurança de um indivíduo que está sofrendo uma perseguição quanto aos casos em que este apenas busca 
evitar o risco de que ela ocorra. Ademais, este elemento não possui apenas caráter subjetivo, mas também objetivo, conforme define o ACNUR:

A este elemento de temor - que é um estado de espírito e uma condição subjetiva - é acrescentada a qualificação "com razão". Isto implica que não é só o estado de espírito da pessoa interessada que determina a condição de refugiado, mas que esse estado de espírito seja baseado em uma situação objetiva. (ACNUR, 2004, p. 12).

A extraterritorialidade é certa e não apresenta exceções, de forma que somente restará configurado o refugiado nos casos em que seu deslocamento forçado ultrapassar os limites de seu país de origem ou do país de sua habitual residência. Assim, não se aplicam as normas de proteção aos refugiados em casos de migração interna visto que o individuo permanecera sob a jurisdição do respectivo Estado e possível perseguidor (PEREIRA, 2009).

Existem algumas cláusulas de exclusão da aplicabilidade do Direito Internacional aos Refugiados, quais sejam: para pessoas que já estão protegidas ou assistidas por algum órgão diverso do ACNUR, mas pertencente à ONU; aos que já possuem direitos e obrigações civis como se nacional fossem no país onde solicitam refúgio e àqueles contra os quais haja fundada suspeita de autoria de crimes contra a paz (PEREIRA, 209).

Importa ressaltar ainda a existência de algumas cláusulas de cessação do refúgio, que ocorrerão nos seguintes casos: quando o país de origem ou nacionalidade retomar a proteção; recuperar-se a nacionalidade perdida; aquisição de nova nacionalidade onde gozará de proteção; repatriação voluntária; cessação das condições de temor e perseguição que ensejaram a solicitação de refúgio, podendo o indivíduo retornar para seu país de origem ou local de sua residência habitual, quando não possuidor de nacionalidade (PEREIRA, 2009).

Nacionalmente, a Lei 9.474/97 é que define os mecanismos para a implementação do Estatuto dos Refugiados de 1951, ratificado pelo Brasil e regulamente, em geral, o direito de refúgio internamente. Tal legislação é um produto da cooperação entre o Estado Brasileiro, o Alto Comissariado das Nações Unidas para Refugiados (ACNUR) e a sociedade civil, sendo considerada uma das mais avançadas no mundo (ALVES, 2018).

\section{MIGRAÇÕES CLIMÁticAS E O RECONHECIMENTO DE UMA NOVA CATEGORIA: "REFUGIADOS AMBIENTAIS"}


A preocupação com o meio ambiente vem ganhando destaque nos últimos anos. Este tem sido um tema recorrente nos encontros internacionais governamentais, científicos e sociais. Isso ocorre principalmente pela crescente busca de conscientização sobre a limitação dos recursos naturais e as inevitáveis respostas da natureza à ação humana de degradação ao meio ambiente (RODRIGUES; LAMPIER JUNIOR, 2017).

Ao mesmo passo em que a globalização intensificou as migrações voluntárias em busca de melhores condições de vida, a ação humana causadora do aquecimento global e inúmeras catástrofes ambientais, além daquelas decorrentes da própria natureza, intensificou o deslocamento forçado de pessoas por impossibilidade de permanecerem em seus locais de origem, os quais foram gravemente afetados por estes eventos.

Neste sentido, no que se referem à causa do deslocamento, as migrações climáticas podem ser compreendidas como: antropogênicas, quando existe a intervenção humana no meio ambiente provocando a degradação e consequentemente a necessidade de migração; naturais, "quando os eventos ambientais ocorrem sem a interferência humana no meio"; e mistas, quando há a influência das duas causas anteriores "concomitantemente e em graus diversos" (CLARO, 2018).

Muitas são as classificações dadas aos eventos da natureza causadores das migrações forçadas, no entanto alguns deles podem ser destacados: desmatamento, o aumento do nível do mar, a desertificação e ocorrência de secas, a degradação do solo, a degradação do ar e a degradação da água; sejam eles isolados ou em conjunto. Deve-se notar que as causas do deslocamento podem ser naturais propriamente ditas ou indiretamente naturais, que são aquelas causadas pela ação do homem, como os acidentes industriais (PEREIRA, 2009).

Ao analisar as migrações ambientais, Castillo (2011, p. 14-15) as classifica em três grandes grupos, de acordo com as razões que ensejaram o deslocamento. São elas: os deslocados ambientais temporários, que deixam sua habitação temporariamente por pressões ambientais, e que tem grande probabilidade de retorno; os deslocados permanentes, em razão de mudanças drásticas em seu território, como a construção de represas e, por fim, os deslocados permanentes em razão de uma degradação progressiva em seu território, o qual já não apresenta mínimas condições de vida. 
Sabendo-se que a configuração do refúgio se dá no campo das migrações ou deslocamentos forçados e reconhecendo-se que muitos são os desastres ambientais causados muitas vezes pela ação humana degradando a natureza e que em razão disso muitos indivíduos devem deixar seus locais de origem involuntariamente para que possam sobreviver, é inegável o surgimento da necessidade de se categorizar este grupo de pessoas no campo dos refugiados. Todavia, tal definição sempre foi uma tarefa árdua e problemática.

Como visto a definição para refugiados trazida pela Convenção de 1951 e o Protocolo de 1967 é taxativa e restritiva, assim, não se considera adequada a expressão "refugiados ambientais", já que esta hipótese não está prevista no referido texto normativo, motivo pelo qual na maioria das vezes ela é utilizada com aspas.

A respeito do conceito de refugiados ou migrantes ambientais, a Organização Internacional para as Migrações (OIM) assim define:

O termo aplica-se a pessoas ou grupos de pessoas que, devido a alterações ambientais repentinas ou progressivas que afetam negativamente as suas vidas ou as suas condições de vida, veem-se obrigados a deixar as suas residências habituais, ou escolhem fazê-lo, temporariamente ou permanentemente, e que se deslocam dentro do próprio país ou para o estrangeiro. (ORGANIZAÇÃO INTERNCAIONAL PARA AS MIGRAÇÕES, 2010).

Destaca-se ainda a definição dada pelo Programa das Nações Unidas para o Meio Ambiente criado na Conferência da ONU em Estocolmo (1972), que afirmou ser este um grupo de pessoas que são "obrigadas a abandonar temporária ou definitivamente a zona onde tradicionalmente viviam, devido ao visível declínio do ambiente, perturbando a sua existência e ou a qualidade da mesma de tal maneira que a subsistência dessas pessoas entrasse em perigo" (PEREIRA, 2009, p. 107).

A expressão "refugiados ambientais" foi utilizada pela primeira vez em 1970 por Lester Brown, quando se referiu ao grupo de pessoas que na época estavam nesta condição, todavia, foi em 1985 que efetivamente a expressão passou a ser adotada. Na referida ocasião, Essan El-Hinnawi se manifestou no relatório do Programa das Nações Unidas para o Meio Ambiente (INEP) a respeito do grande número de migrantes que saíram de seus países por catástrofes ambientais, fossem elas por causas naturais ou humanas. Não obstante, desde a Declaração das Nações Unidas sobre o Ambiente Humano de Estocolmo (1972), a referida expressão tem sido utilizada (CLARO, 2018). 
Por vezes, é possível que haja dificuldade na distinção entre refugiados ambientais e econômicos, visto que no segundo caso muitas vezes a causa das más condições financeira e de vida é decorrente de algum evento ambiental, principalmente as degradações que ocorrem lentamente ao longo do tempo. Nestes casos, é necessário analisar se o fator decisivo que ensejou a migração foi a questão ambiental ou os outros fatores socioeconômicos (SALIBA; DO VALLE, 2017).

A relação entre a seca e a fome é um bom exemplo para ilustrar a dificuldade de distinção entre as migrações forçadas por razões ambientais ou econômicas. Neste caso, tendo-se que analisar qual foi o motivo direto causador do deslocamento, muitos autores apontam a seca fator determinante, considerando a fome como uma consequência e, portanto, motivo indireto par o deslocamento, situação na qual estaria configurado o "refugiado ambiental", todavia tal entendimento não é uma regra, podendo ocorrer variações caso a caso (PEREIRA, 2009).

A figura do "refugiado ambiental" pode ser entendida como genérica, estando aderidas a ela as espécies como refugiados climáticos, que são aqueles que são obrigados a migrar por razão da alta variabilidade climática no seu lugar de origem e os refugiados da conservação, que são aqueles oriundos de locais que foram transformados em áreas de preservação ambiental e que foram, portanto, coagidos a deixarem seu local de origem (CLARO, 2018).

Embora as migrações por questões climáticas tenham passado a figurar nas pautas de debates internacionais, por muito tempo a preocupação limitou-se à análise de terminologias e não efetivamente discutiram-se as condições em que vivem os refugiados ambientais e a necessidade de proteção de seus direitos. Tal fato se justifica principalmente pela ausência de previsão normativa desta categoria de refugiados. (CLARO, 2018).

Seja refugiado, migrante ou deslocado, não é a terminologia ou definição que deve ser o foco principal nessa discussão, mas sim o reconhecimento formal e material destes grupos de pessoas que se encontram em situações vulneráveis e desprovidos de proteção aos seus direitos por não enquadrarem-se nas hipóteses atualmente previstas nos diplomas normativos do direito internacional e direito interno. 
Destaca-se que o único tratado internacional que enquadrou a categoria dos refugiados ambientais foi a Convenção Árabe de 1994, o qual não se limitou às disposições da Convenção Internacional de 1951. Todavia, como não houve ratificação por nenhum Estado, o referido tratado não surtiu nenhum efeito vinculante. Sendo assim, pode-se afirmar que não existe nenhum texto normativo que disponha a existência dessa categoria de refugiados, o que fortalece a total vulnerabilidade deste grupo de indivíduos. (SALIBA; DO VALLE, 2017).

\section{LIMITAÇÕES DO DIREITO INTERNACIONAL E ALTERNATTIVAS À PROTEÇÃO DOS "REFUGIADOS AMBIENTAIS"}

O Direito Internacional dos Refugiados prevê um rol de situações nas quais se caracteriza o deslocamento forçado. Todavia, a interpretação para tal disposição é restritiva, de forma que muitas outras hipóteses não previstas expressamente deixam de ser abrangidas. É o caso dos refugiados ambientais. O diploma normativo restringe-se somente àqueles que sofrem perseguição, grave ou iminente violação de direitos civis ou políticos.

Como exposto, o Estatuto dos Refugiados, firmado na Convenção de Genebra de 1951 que foi alterado pelo Protocolo de 1967, dispõe que "refugiado" é todo aquele que se encontra fora de seu país e impossibilitado de retornar, "por motivos de raça, religião, nacionalidade, grupo social ou opiniões políticas".

Sendo assim, estão excluídos deste enquadramento os deslocados internos, que não chegam a migrar para outro país, mas são obrigados a deixarem seus locais de origem, e os migrantes por razões diversas daquelas tipificadas, mas que ensejam também o deslocamento forçado, como é o caso dos refugiados ambientais. O fato de estes grupos não serem abarcados pela proteção internacional é um grande desafio atualmente, visto que são sujeitos de direitos que estão sendo violados, ainda que por razões distintas daquelas previstas nas normas internacionais de proteção aos refugiados.

Como visto o texto normativo presente na Convenção de 1951, que trata das hipóteses que configuram a figura dos refugiados ambientais, faz referencia à "perseguição" como condição para tal enquadramento. Todavia, embora a Convenção não traga uma definição para este termo e ao mesmo tempo traga um rol restritivo, o Alto Comissariado das Nações Unidas para Refugiados (ACNUR) prevê: 
Para avaliar se outras ameaças ou ações prejudiciais podem configurar uma perseguição, é preciso analisar as circunstâncias específicas de cada caso, incluindo o elemento subjetivo a que se fez referência em parágrafos anteriores. O caráter subjetivo do temor de perseguição exige uma apreciação das opiniões e sentimentos da pessoa em questão. (ACNUR, p. 14).

Quando se fala na proteção aos "refugiados ambientais", uma das dificuldades que se encontra é exatamente a ausência desta condição. Ainda que alguns estudiosos afirmem que a conduta omissiva do Estado em casos de desastres naturais é uma forma de perseguição, não existe conformidade em tal sentido, visto que na maioria dos casos a deficiência é generaliza, o que compromete o atendimento de um segundo requisito, a perseguição a um grupo social específico, o qual deve estar "conectado por características substanciais e imutáveis para além do risco de perseguição - isto é, é preciso que se trate de um grupo social particular mesmo quando não há qualquer perseguição" (SALIBA; DO VALLE, 2017, p. 16).

Sendo assim a categoria "refugiado ambiental" não possui enquadramento técnico e jurídico no direito internacional dos refugiados e além de não preencher o requisito "perseguição", não se adequa a nenhuma das cinco possíveis situações elencadas no artigo $1^{\circ}$ do Estatuto dos Refugiados. "Tal ausência configura-se como uma limitação à possibilidade de se contemplar os chamados refugiados ambientais com a proteção oriunda do instituto jurídico do refúgio" (PEREIRA, 2009, p. 114).

Não obstante, o nexo de causalidade entre o evento ambiental e o deslocamento forçado é obrigatório e determinante para a configuração do refúgio, ainda que se alcance a legítima aplicação do direito internacional dos refugiados aos migrantes por questões ambientais, o que, conforme já exposto, pode ser uma tarefa muito difícil em alguns casos (PEREIRA, 2009).

Embora decorrente de eventos que não se limitam a fronteiras territoriais e que são considerados uma grande preocupação internacional, as migrações ambientais não é tema de consensualidade entre os Estados, visto que muitos ainda não reconhecem essa categoria de refugiados e se negam a oferecê-los proteção, principalmente pela inexistência de uma norma específica regularizando a situação deste grupo de pessoas (ALVES, 2018).

Outros importantes documentos internacionais surgiram prevendo maior abrangência, todavia, os deslocados por questões ambientais continuam sem o formal 
enquadramento na figura de refugiados, visto que não se trata de uma hipótese expressamente prevista.

Há muito tempo, o que se tem adotado é a tentativa de uma analogia de proteção dos deslocados ambientais com os demais refugiados tipificamente configurados. Todavia, tal medida tem-se demonstrado precária e inadequada, visto que cada categoria requer um tratamento específico baseado nas particularidades de cada situação para que a tutela dos direitos destes indivíduos seja efetiva (SALIBA; DO VALLE, 2017).

Ao tratar sobre o tema, Carolina Claro evidencia alguns elementos básicos do conceito de refugiados ambientais que devem ser compreendidos: é não convencional; é migrante forçado; sua migração pode ser interna ou internacional, sendo que no primeiro caso continuará sendo indicado com a mesma terminologia; sua migração pode ser temporária ou permanente e têm como razão principal a vulnerabilidade ambiental, ainda que presentes outras (2018, p. 78-79).

Importa salientar que a falta de previsão expressa de medidas de proteção aos deslocados por catástrofes ambientais interfere diretamente na recepção e tratamento destes nos países destinatários. Isso significa que a ausência de uma proteção específica torna esses países desobrigados de qualquer medida protetiva em relação a esta categoria de refugiados. Neste contexto, resta a busca por uma proteção complementar e local. (SALIBA; DO VALLE, 2017).

Diante dos inúmeros desastres naturais que vêm ocorrendo em todo o planeta e do crescente deslocamento forçado de pessoas por não possuírem, ainda que momentaneamente, possibilidade de continuarem suas vidas nos países de sua nacionalidade em razão de tais catástrofes, é incontestável a necessidade de haver uma iniciativa no sentido de regulamentar e tutelar os direitos dessas pessoas, as quais podem ser faticamente enquadradas como refugiados ambientais.

Para tanto, é necessário tomar consciência de que a dignidade humana destes deslocados por catástrofes ambientais está sendo atingida e que é urgente a necessidade de se adotar medidas capazes de tutelar os direitos inerentes a ela. Tal necessidade está no fato de 
os deslocados serem sujeitos de direitos, ainda que não estejam formalmente enquadrados na figura de refugiados.

Embora haja uma lacuna no direito internacional sobre refugiados ambientais, é preciso existir de alguma forma a proteção a este considerável grupo de pessoas, o que pode ser feito por meio da aplicação dos princípios e disposições do direito ambiental internacional e direitos humanos. Destaca-se aqui a Declaração Universal de Direitos Humanos (1948), o Pacto de Direitos Civis e Políticos, o Pacto dos Direitos Econômicos, Sociais e Culturais (1966) e a Declaração das Nações Unidas sobre o Ambiente Humano de Estocolmo de 1972 que estabelece no Princípio 1, o direito fundamental à liberdade, à igualdade e ao desfrute de condições de vida adequadas em um ambiente cuja qualidade lhe permita viver com dignidade e bem-estar.

A Declaração Universal dos Direitos Humanos - DUDH (1948) é clara ao prever que "todo ser humano tem o direito de deixar qualquer país, inclusive o próprio, e a este regressar" (ONU, 1948), especialmente quando este se encontrar em uma situação de vulnerabilidade e perseguição, sendo assim, o direito internacional não pode se furtar de sua responsabilidade de proteção a esta categoria de pessoas, ainda não haja documento normativo especifico prevendo os instrumentos de proteção aos seus direitos e garantias.

Destaca-se o disposto no artigo 13 da Declaração e Programação de Ação de Viena, formulada na Conferência Mundial sobre Direitos Humanos em 1993, ao prever que os Estados devem criar condições capazes de "garantir o gozo pleno e efetivo dos Direitos Humanos" e, ainda "eliminar todas as violações dos Direitos Humanos e respectivas causas, bem como os obstáculos ao gozo desses direitos" que corrobora as disposições da DUDH de 1948 e a responsabilidade dos Estados em relação à proteção dos indivíduos solicitantes de refúgio por razões climáticas.

Veja-se, mais especificamente, o disposto no artigo 23 da Declaração de Viena (1993):

A Conferência Mundial sobre Direitos Humanos reafirma que todos, sem distinção de qualquer espécie, têm o direito de procurar e obter, noutros países, asilo contra as perseguições de que sejam alvo, bem como o direito de regressar ao seu próprio país.

[...] 
A Conferência Mundial sobre Direitos Humanos reconhece que, face às complexidades da crise global de refugiados e conformemente à Carta das Nações Unidas, aos relevantes instrumentos internacionais e à solidariedade internacional, e num espírito de partilha de responsabilidades, se torna necessária uma abordagem global por parte da comunidade internacional, em coordenação e cooperação com os países afetados e com as organizações relevantes, tendo presente o mandato do Alto Comissariado das Nações Unidas para os Refugiados. Tal deverá incluir o desenvolvimento de estratégias para abordar as causas remotas e os efeitos das movimentações de refugiados e outras pessoas deslocadas, o reforço de mecanismos de alerta e resposta em caso de emergência, a disponibilização de proteção e assistência efetivas, tendo presentes as necessidades especiais das mulheres e crianças, bem como a obtenção de soluções duradouras, primeiramente através da solução preferível do repatriamento voluntário dignificante e seguro, e incluindo soluções tais como as adotadas pelas conferências internacionais sobre refugiados. A Conferência Mundial sobre Direitos Humanos sublinha as responsabilidades dos Estados, particularmente as que se relacionam com os países de origem.

\section{$[\ldots]$}

Em conformidade com a Carta das Nações Unidas e os princípios de Direito Humanitário, a Conferência Mundial sobre Direitos Humanos realça ainda a importância e a necessidade da assistência humanitária às vítimas de todas as catástrofes, quer naturais quer causadas pelo ser humano.

Há, neste sentido, uma forte relação entre a proteção aos refugiados, um dos ramos dos Direitos Humanos e o Direito Internacional Ambiental, visto que a falta daquele pode afetar diretamente as disposições ambientais internacionais, e vice-versa. Tal relação encontra-se, por exemplo, na Declaração do Rio de 1992, quando afirma que a natureza integral interdependente da terra é nosso lar.

O ideal é que se crie um documento internacional prevendo a proteção expressa aos refugiados ambientais, todavia, enquanto tal medida permanece apenas como uma mera expectativa deve-se recorrer aos demais meios existentes para que os direitos humanos e fundamentais dos deslocados forçados por questões ambientais não sejam violados.

Ademais, considerando que os problemas ambientais não se limitam a fronteiras, é necessário que se tenha por pressuposto o princípio da solidariedade internacional para que se possa alcançar uma efetiva proteção a esta categoria de refugiados.

\section{CONCLUSÃO}

A problemática apresentada revela uma crise humanitária em constante crescimento cuja solução requer, com urgência, a tomada de medidas que proporcionem a definição legal para a situação de "refugiados ambientais" e a previsão de mecanismos de proteção aos 
mesmos, medidas estas que devem estar pautadas nas diretrizes do direito internacional ambiental e direitos humanos.

É flagrante a violação sofrida pelos "refugiados ambientais", tendo em vista que não há instrumentos de garantia capazes de tutelar seus direitos e a sua própria dignidade humana. A comunidade internacional precisa se despertar pra tal fato e tomar medidas urgentes.

Deve-se ter como objetivo a criação de instrumentos normativos que regularizem a situação deste grupo de pessoas e que prevejam as medidas a serem tomadas internacionalmente e internamente pelos países signatários e receptores desses refugiados. Em meio à degradação deve-se prezar pela proteção do direito humanitário, de forma que todos possam viver em um ambiente equilibrado, saudável e de paz.

\section{REFERÊNCIAS BIBLIOGRÁFICAS}

BRASIL. Lei no 9.474, de 22 de julho de 1997. Disponível em: < http://www.planalto.gov.br/ccivil_03/LEIS/L9474.htm> Acesso em: 11 ago. 2019.

. Lei no 9.474, de 22 de Julho de 1997. Disponível em: <

http://www.planalto.gov.br/ccivil_03/LEIS/L9474.htm> Acesso em: 10 ago. 2019. BROWN, Lester. Plan B: rescuing a planet under stress and civilization in trouble. London: Norton \& Company, 2003. p. 100. (tradução livre).

CASTLES, Stephen. Globalização, transnacionalismo e novos fluxos migratórios. 2005. Cap. 1: As migrações internacionais no limiar do século XXI: Questões e tendências globais.

CLARO, Carolina de Abreu Batista. A proteção dos "refugiados ambientais" no direito internacional. 2015. 328 f. Tese (Doutorado em Direito Internacional). Universidade de São Paulo, 2015.

Convenção relativa ao Estatuto dos Refugiados (1951). Disponível em: < https://www.acnur.org/fileadmin/Documentos/portugues/BDL/Convencao_relativa_ao_Estatu to_dos_Refugiados.pdf>. Acesso em: 10 ago. 2019.

Declaração de Cartagena. Disponível em:

https://www.acnur.org/fileadmin/Documentos/portugues/BD_Legal/Instrumentos_Internacion ais/Declaracao_de_Cartagena.pdf Acesso em: 10 ago. 2019.

JUBILUT, Liliana Lyra; RAMOS, Érika Pires; CLARO, Carolina de Abreu Batista; CAVEDON-CAPDEVILLE, Fernanda de Salles. (Org.). "Refugiados Ambientais". Boa Vista: Editora da UFRR, 2018. 
OIM. Direito Internacional da Migração. Glossário da Migração. № 22. Editora: Organizaçao Internacional para Migrações. Disponível: <

https://publications.iom.int/system/files/pdf/iml22.pdf> Acesso em: 10 ago. 2019.

ONU. Declaração de Estocolmo sobre o ambiente humano - 1972. Disponível em: <

Declaração de Estocolmo sobre o ambiente humano - 1972> Acesso em: 11 ago. 2019.

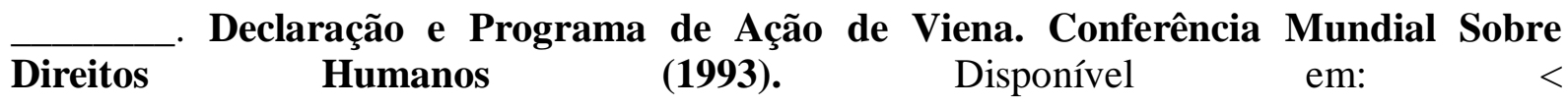
http://www.direitoshumanos.usp.br/index.php/Sistema-Global.-

Declara\%C3\%A7\%C3\%B5es-e-Tratados-Internacionais-de-

Prote $\%$ C3\%A7\%C3\%A3o/declaracao-e-programa-de-acao-de-viena.html> Acesso em: 24 de ago. 2019.

em: <

. Declaração do Rio sobre Meio Ambiente e Desenvolvimento (1992). Disponível

http://www.meioambiente.pr.gov.br/arquivos/File/agenda21/Declaracao_Rio_Meio_Ambient e_Desenvolvimento.pdf> Acesso em: 11 ago. 2019.

Declaração Universal dos Direitos Humanos (1948). Disponível em: < http://www.meioambiente.pr.gov.br/arquivos/File/agenda21/Declaracao_Rio_Meio_Ambient e_Desenvolvimento.pdf> Acesso em: 11 ago. 2019.

OUA. Convenção da Organização de Unidade Africana (OUA). Disponível em: http://refugiados.net/1cpr/www/legislacao/leis/asilo2/2couaapr.html Acesso em: 10 ago. 2019.

PACÍFICO, Andrea Pacheco e GAUDÊNCIO, Marina R. B. (2014). A Proteção dos deslocados ambientais no Regime Internacional dos Refugiados. In: Revista Interdisciplinar da Mobilidade Humana (REMHU), v. 22, n. 43. Disponível em http://www.scielo.br/pdf/remhu/v22n43/v22n43a09.pdf.

PEREIRA, Luciana Diniz Durães. O Direito Internacional Dos Refugiados: Análise Crítica Do Conceito "Refugiado Ambiental”. 2009. 171 f. Dissertação (Mestrado em Direito Público). Pontifícia Universidade Católica de Minas Gerais, 2009.

Protocolo de 1967 relativo ao Estatuto dos Refugiados. <Disponível em: https://www.acnur.org/fileadmin/Documentos/portugues/BD_Legal/Instrumentos_Internacion ais/Protocolo_de_1967.pdf?file=fileadmin/Documentos/portugues/BD_Legal/Instrumentos_I nternacionais/Protocolo_de_1967> Acesso em: 10 ago. 2019.

RAMOS. Érika Pires. Refugiados Ambientais: em busca de reconhecimento pelo direito internacional. 2011. 150 f. Tese (Doutorado em Direito Internacional). Universidade de São Paulo, 2011. 
SILVA, Carla Ribeiro Volpini. A proteção internacional dos refugiados ambientais fundamentada nos mecanismos de proteção do direito internacional dos refugiados. Rev. Jurídica Unicuritiba, Curitiba, vol. 03, n . 48, p. 428-457, 2017.

SILVEIRA, Patricia Azevedo. Refugiados Ambientais e sua Proteção Jurídica no Direito Internacional. Rev. EMERJ, Rio de Janeiro, v. 15, n. 58, p. 247-260, abr.-jun. 2012. 